\title{
THE ROLE OF THE AMERICAN RED SQUIRREL (TAMIASCIURUS HUDSONICUS) IN THE EVOLUTION OF SEROTINY IN LODGEPOLE PINE (PINUS CONTORTA)
}

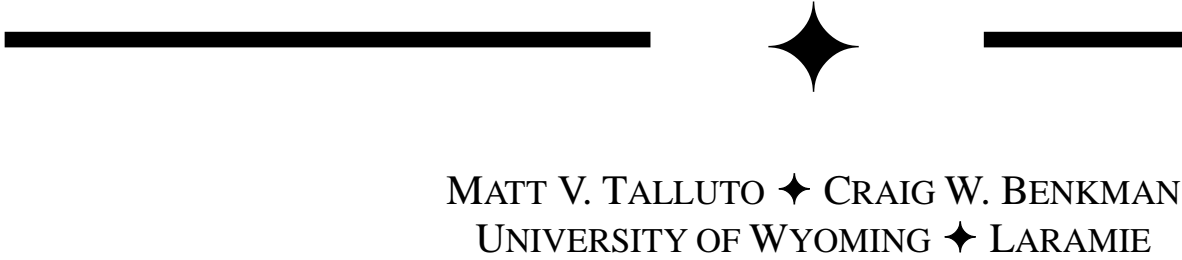

\section{$\uparrow \quad$ AbSTRACT}

Coevolutionary interactions can have dramatic effects on the structure and function of ecosystems, particularly when spatial structure leads to local adaptation. Here we report on an ongoing study of the interaction between lodgepole pine and its primary pre-dispersal seed predator, the American red squirrel. Lodgepole pine is serotinous, meaning seeds are held in closed cones until released by the heat of a fire. Serotiny has been shown to increase seedling density following stand replacing fire, and can have far-reaching ecosystem- and communitylevel implications. Red squirrels are negatively associated with serotiny at broad geographic scales, and may select against the serotinous trait. This project aims to examine the correlation between red squirrel density and the frequency of serotiny in lodgepole pine forests and the mechanisms underlying potential selection against serotiny by red squirrels. Specifically, we will determine whether this correlation is present when other factors affecting serotiny (i.e., fire frequency, elevation) are held constant, whether the fitness of serotinous trees is reduced in the presence of red squirrels, and what factors control the density of red squirrels. Preliminary results indicate that serotiny and squirrel density is strongly negatively correlated, but only at low elevations. Serotiny was nearly absent at high elevations, but squirrel density varied as much as at low elevations, suggesting that serotiny does not control squirrel density, but that increasing squirrel density may lead to increasing selection against serotiny.

\section{$\uparrow \quad$ INTRODUCTION}

Many natural systems are spatially structured as a result of variation in either biological interactions or abiotic forcing (Fortin and Dale 2005; Blanchet et al. 2008). This structure results in heterogeneity in ecological interactions, potentially leading to patchiness in the strength of reciprocal selection in interacting species. If selection is strong enough to overcome gene flow, local adaptation to species interactions and/or abiotic conditions can result. This project investigates a potential geographic mosaic involving the interaction between Rocky Mountain lodgepole pine (Pinus contorta latifolia, hereafter "lodgepole pine"), a serotinous, fire-adapted conifer, and its primary seed predator, the American red squirrel (Tamiasciurus hudsonicus; hereafter "red squirrel").

Lodgepole pine is serotinous throughout most of its range. Serotiny, the retention of seeds in woody structures held in the canopy, is a common fire adaptation in many conifers where cones are held closed by resin that melts when exposed to the heat of a fire, releasing the seeds into favorable postfire conditions (i.e., high nutrients and light; Keeley and Zedler 1998). Serotiny in lodgepole pine has been shown to have profound ecological consequences, and fire-mediated effects can be particularly strong. In the Greater Yellowstone Ecosystem, stands of lodgepole pine having higher frequencies of serotiny recovered from widespread fires in 1988 at much higher seedling densities than stands having lower frequencies of serotiny, leading to postfire differences in net primary productivity, nutrient cycling, and community assembly (Turner et al 2003, 2004). 
The frequency of serotiny varies greatly, both within continuous forest patches at scales of 1$10 \mathrm{~km}$ (Tinker et al. 1994), and among mountain ranges (Benkman and Siepielski 2004). A number of studies have addressed patterns of serotiny in relation to hypothesized selective agents. Fire frequency, size, and intensity are positively correlated with the frequency of serotiny in several species, and fire is the most common hypothesized agent of selection favoring serotiny (Perry and Lotan 1979; Gauthier et al. 1996; Enright et al. 1998; Schoennagel et al. 2003). Smith (1970) hypothesized that predation by red squirrels (Tamiasciurus hudsonicus) would favor increased serotiny, as harder cones reduce red squirrel foraging efficiency. More recent work has indicated that red squirrels may select for decreased serotiny (Benkman and Siepielski 2004), suggesting that escape from predation by dispersing seeds quickly and reducing the period of vulnerability (with nonserotinous cones) may be a more effective evolutionary strategy than increasing seed defense.

Previous work has largely focused on describing patchiness in serotiny relative to patterns in fire frequency. Several authors have described a negative relationship between serotiny and elevation, a pattern which may be due to reduced fire frequency at higher elevations (Tinker et al. 1994; Schoennagel et al. 2003). In a study conducted in the Greater Yellowstone Ecosystem (GYE), Schoennagel et al. (2003) estimated 135-185 year fire return intervals at low elevations, and 280-310 year intervals at high

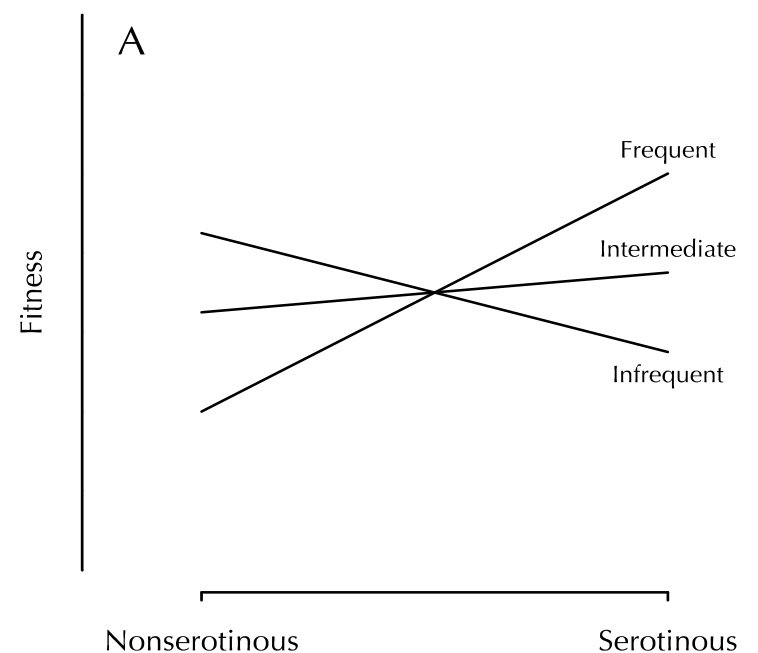

elevations, so the hypothesis that the elevational gradient in serotiny is due to differences in fire frequency is plausible. However, even when elevation is considered, there is often considerable unexplained variation in the frequency of serotiny at landscape scales, particularly at lower elevations (Tinker et al. 1994).

Pre-dispersal seed predation from red squirrels may explain some of the remaining variation in the frequency of serotiny, and the very high frequency of serotiny observed in forests where squirrels have historically been absent appears to support this hypothesis (Benkman and Siepielski 2004). Red squirrels feed on both serotinous and nonserotinous cones, but the duration during which nonserotinous cones are available is limited; squirrels only harvest non-serotinous cones in late summer, when the cones are nearly ripe but have not yet opened to disperse seeds (Smith 1968). In contrast, serotinous cones are eaten and stored in caches yearround, resulting in a greatly depleted canopy seed bank and decreasing the relative fitness of serotinous trees (Elliott 1988; Benkman and Siepielski 2004). Therefore, the overall strength of selection on serotiny might be a composite of opposing directional selection (from fire favoring serotiny and seed predation favoring the open-coned phenotype; Figure 1). Spatial variation in the relative strengths of these two selective forces could then result in the observed pattern of spatial heterogeneity in the frequency of serotiny. The factors controlling red squirrel density

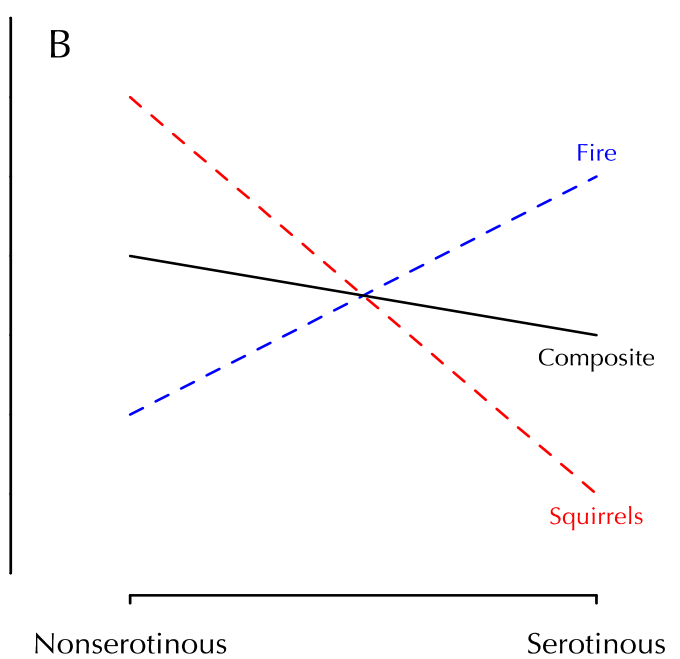

Figure 1. Hypothetical fitness functions for serotiny. A: Fitness plotted under varying fire frequencies; serotiny is progressively more favored as fire frequency increases. B: In the presence of predation from squirrels, the fitness of each type is a composite resulting from selection from both squirrels (red) and fire (blue), resulting in the nonserotinous form being favored. 
could be crucial in determining spatial patterns in the intensity of selection on serotiny. Squirrels require a stable source of seeds, which is their primary food source. They may also require fungi as a source of water and supplemental nutrition. Finally, antipredator habitat features (e.g., canopy or ground cover) may also be important (Smith 1968; Elliott 1988).

Here we report on an ongoing study of the effects of red squirrel predation on serotiny in lodgepole pine. The goals of the first year of this study were to: 1) Determine if red squirrels were correlated with the frequency of serotiny at a small spatial scale; 2) Investigate what habitat features (e.g., forest structure, elevation, precipitation, etc) predict red squirrel density; and 3) Estimate mortality rates of serotinous and nonserotinous cones to determine if red squirrels select against serotiny.

\section{STUDY AREA}

Our study area included mature lodgepole pine forests throughout Yellowstone National Park, focusing on the central plateau and adjacent areas. A map of plot locations is provided in Figure 2.

\section{$\uparrow \quad$ METHODS}

\section{Plot Selection}

We sampled within 14 plots in 2010. Plots were approximately 25 ha (exact dimensions varied depending on the presence of barriers to sampling necessitating slightly smaller plots). We selected plot locations haphazardly by first identifying candidate locations and then randomly selecting the location of the plot corner. Candidate locations were identified using a GIS layer of vegetation cover to select areas designated as mature lodgepole pine forest. Plot locations were then selected randomly from these areas. If ground truthing revealed a plot was located in an area that was not at least $50 \%$ lodgepole pine, that plot was rejected and a new location was randomly generated.

\section{Red Squirrel Density}

Red squirrels are central place foragers that produce a single large midden (Smith 1968). Because each squirrel produces only one midden, we used midden density as a proxy for squirrel density. To measure midden density, we used distance sampling (Buckland et al. 2001). Within each plot, we walked 8 200-m transects. Transects were oriented north- south on a $2 \times 4$ grid, and were separated from each other by $150 \mathrm{~m}$. Although transects were spaced on a grid, the start location of the grid was random (following Buckland et al. 2004). We recorded the exact distance to each active midden and analyzed the data using Distance 6.0r2 (Thomas et al 2010). When transects intersected barriers (e.g., topographic barriers, meadows, geothermal features), we halted the transect $10 \mathrm{~m}$ from the barrier edge and continued the transect $10 \mathrm{~m}$ from the far edge of the barrier.

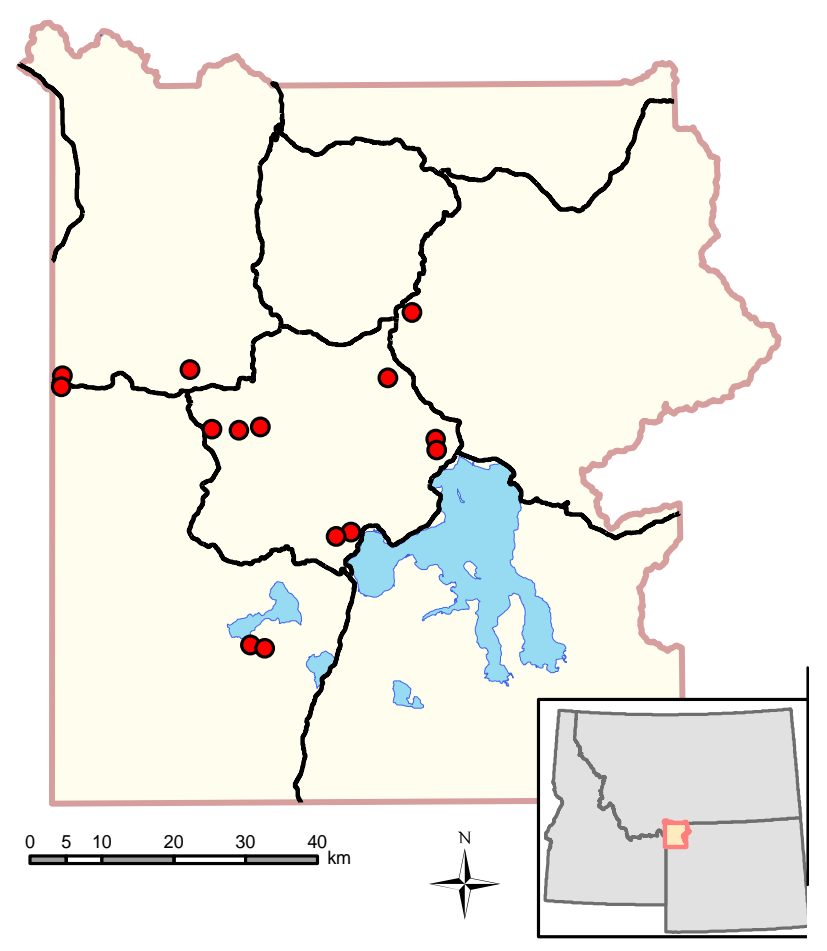

Figure 2. Map of 2010 study sites located in Yellowstone National Park.

\section{Frequency of Serotiny}

We recorded the frequency of serotiny within two $400 \mathrm{~m}^{2}$ square quadrats along each distance sampling transect. These quadrats were centered $50 \mathrm{~m}$ from each transect endpoint. Within each quadrat, we classified all trees according to the proportion of non-weathered closed cones present. We disregarded weathered cones because serotinous cones eventually open after years of weathering, and are not an accurate assessment of whether a tree is serotinous or not. These cones were easily identifiable by their extremely bleached coloring, irregular spacing of cone scales, and highly degraded scale margins. Each tree was placed into one of four categories: < $10 \%$ of cones open, $10-50 \%$ of cones open, $50-90 \%$ of cones open, or $>90 \%$ of cones 
open. Very few $(<5 \%)$ trees were in the intermediate categories, so we lumped these trees with the nearest extreme category (e.g., trees with $10-50 \%$ open cones were categorized as non-serotinous along with those in the $<10 \%$ category). In quadrats with fewer than 20 trees, we categorized the nearest 20 trees.

\section{Forest Structure}

To determine if forest structure influenced squirrel density, we measured basal area and canopy density within each quadrat. We used a Forestry Suppliers 2 BAF prism to estimate living basal area at the center point of each quadrat. We used a Forestry Suppliers convex spherical crown densiometer to estimate canopy density. We made 9 canopy density measurements per quadrat (one at the plot center, one $5 \mathrm{~m}$ from the center in each cardinal direction, and one $10 \mathrm{~m}$ from the center in each direction).

\section{Differential Cone Mortality}

To determine whether squirrels exert selection on serotiny, we established an experiment to study the survival probabilities of cones on serotinous and nonserotinous trees. During August 2010, when green cones were large enough to be easily spotted but not yet ripe enough to be removed by squirrels, we marked 187 trees within $43 \mathrm{~m}$ of active squirrel middens in an area with moderate squirrel density and moderate serotiny. We photographed branches with green cones from each tree. Because predation rates for serotinous trees vary with cone age (Smith 1970), we also photographed branches with young (i.e., brown) and older (i.e., gray) serotinous cones. In summer 2011, we will return to these trees and determine the proportion of cones removed from each tree. We will use these data to compare annual mortality rates for serotinous cones and nonserotinous cones. Furthermore, because serotinous cones are exposed to predation for multiple years, we will calculate total predation risk for serotinous cones as a measure of the probability that a cone produced by a serotinous tree will survive to release its seeds.

\section{Data Analysis}

This is a multiple year study, so data analysis will not be complete until data from all years have been collected. However, we have performed some preliminary analyses, and we report the results of those analyses here.
Distance analyses were performed using AIC model selection to determine the most likely model among model sets. Model sets were constructed using half-normal and hazard rate key functions and expanded using cosine and simple polynomial expansions (see Buckland et al. 2001 for a complete explanation). Models were examined for goodness of fit, heaping, and extreme values. The data were ultimately truncated at $90 \mathrm{~m}$, as data points beyond that distance were found to be contributing little information to the model but were requiring the fitting of excessive numbers of parameters. All analyses were stratified at the plot level, yielding estimates of midden (and thus squirrel) density at the scale of our 25-ha plots.

We used GIS data to calculate elevation, slope, aspect, and mean annual precipitation within each study plot. We then used these variables as predictors in generalized linear model (GLM) with squirrel density as the response. To determine if squirrel density affected serotiny, I used squirrel density along with the above variables as predictors of serotiny in GLMs with logit link functions and binomial errors. I examined all 2-way combinations of variables (the small sample size prevented larger models) and performed model selection using AICc (Burnham and Anderson 2002).

\section{$\uparrow \quad$ PREliminary ReSUlts}

Analysis of distance sampling data yielded squirrel density estimates ranging from 0.44 to 5.91 individuals/ha. Of the variables we considered (percent serotiny, canopy cover, basal area, elevation, slope, aspect, soil texture, MAP, and stand age), canopy cover and serotiny best predicted squirrel density $(\ln [$ density +0.1$]=2.2-5.3 \times$ canopy cover $-1.5 \times$ serotiny, Adj. $\left.R^{2}=0.46, P=0.01\right)$, with both predictors being negatively correlated with squirrel density. Other models are not considered here, as they were much less well supported and were > 2 AIC units from this best model (Burnham and Anderson 2002). However, we also found a negative relationship between MAP and red squirrel density, although this appeared to be driven largely by two influential data points (not shown). Further data collection will focus on improving sample sizes to test a more complete model space and on sampling a larger variety of precipitation regimes to determine if precipitation in fact affects squirrel density. 

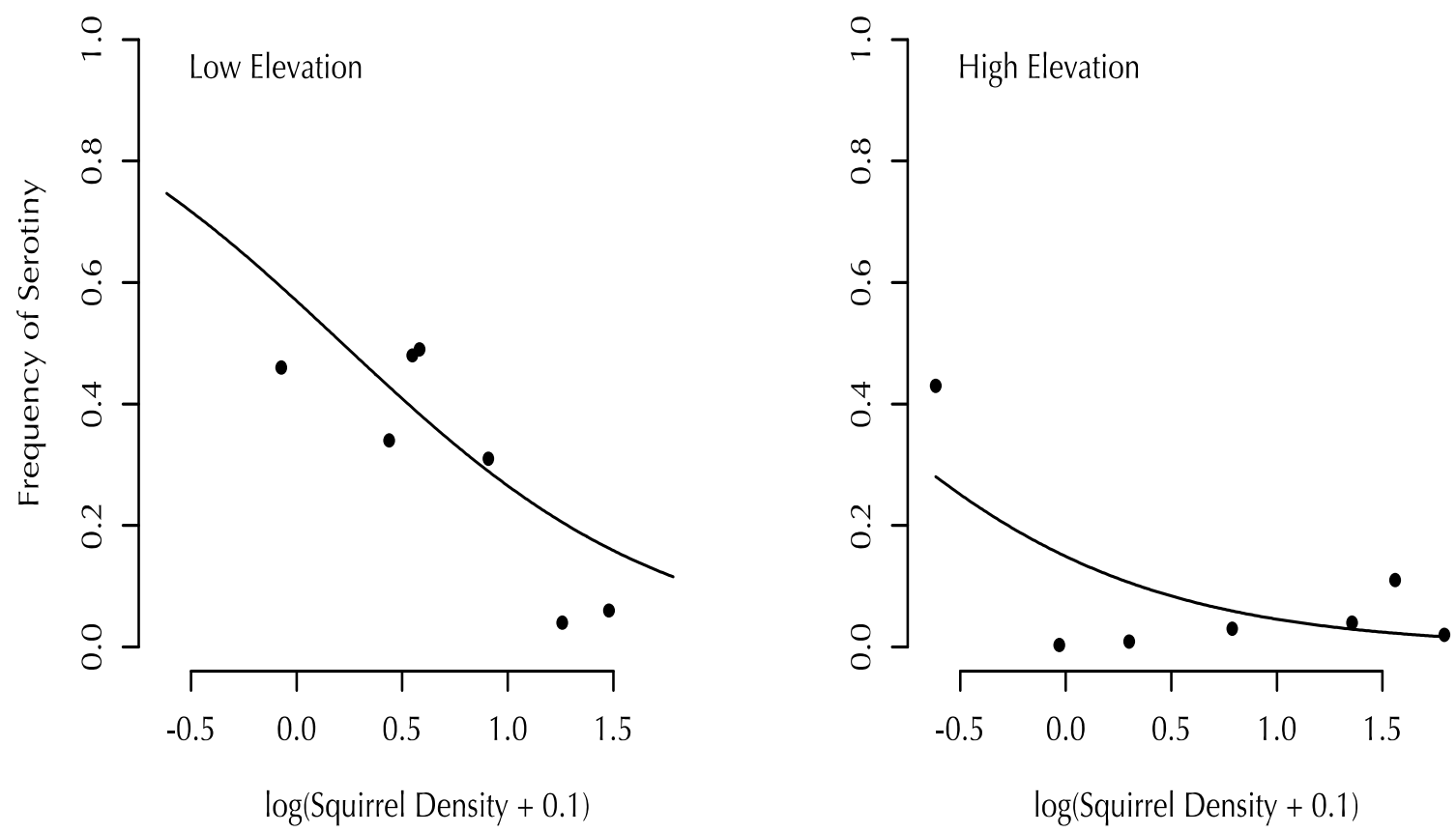

Figure 3. Relationship between squirrel density and the frequency of serotiny at high $(>2458 \mathrm{~m})$ and low elevations.

Only squirrel density and elevation were predictive of the frequency of serotiny; models containing other predictors performed poorly $(\triangle \mathrm{AIC}$ $>2$ ). Elevation was negatively correlated with serotiny, a result that was expected based on previous findings (Tinker et al. 1994). Squirrel density was negatively correlated with serotiny (spearman $\rho=$ -0.25 ). Further data exploration revealed that this relationship was driven by a strong correlation at low elevations $(\leq 2458 \mathrm{~m} ; \rho=-0.64)$; there was essentially no correlation between serotiny and squirrel density at high elevation sites (> $2458 \mathrm{~m} ; \rho=$ 0.036; Figure 3). A GLM with binomial errors revealed a significant relationship between red squirrel density and the frequency of serotiny when elevation was also included as a predictor for serotiny $(P<0.01)$.

\section{MANAGEMENT IMPLICATIONS}

The frequency of serotiny has a large effect on postfire recovery in lodgepole pine forests; previous research has shown that seedling densities following a stand replacing fires are several orders of magnitude higher in highly serotinous stands (Turner et al. 2003). Thus, serotiny is a keystone trait, in that its frequency determines seedling density, which cascades to a number of ecosystem- and communitylevel processes (Turner et al. 2004). If the intensity of predation from red squirrels affects the frequency of serotiny at relatively local (i.e., < 100 ha) scales, then understanding how squirrels affect serotiny and what factors determine predation intensity can yield important predictive information about how forests will respond to fire. This information can be used to construct a model predicting the frequency of serotiny that incorporates input from both fire frequency and squirrel predation intensity. Furthermore, if climate change is expected to drive changes in fire frequency or in the distribution of red squirrels, such changes can be incorporated into the model to investigate future expected changes to the distribution of serotiny on the landscape and thus to the expected outcome of stand-replacing fires.

\section{$\uparrow \quad$ ACKNOWLEDGEMENTS}

The University of Wyoming Program in Ecology provided financial support via its EPSCoR grant. Additional support was provided via the Department of Zoology and Physiology at the University of Wyoming. We thank the UW-NPS Research Station and Yellowstone National Park for essential logistical support. Daniel Tinker and Christie Hendrix provided considerable assistance in the design and implementation of this project. 


\section{$\uparrow \quad$ LiTERATURE CITED}

Benkman CW, Siepielski AM. 2004. A keystone selective agent? Pine squirrels and the frequency of serotiny in lodgepole pine. Ecology 85:2082-2087.

Blanchet FG, Legendre P, Borcard D. 2008. Modelling directional spatial processes in ecological data. Ecol Model 215:325-336.

Buckland ST, Anderson DR, Burnham KP, Laake JL, Borchers DL, Thomas L. 2001. Introduction to distance sampling: Estimating abundance of biological populations. Oxford (UK): Oxford University Press.

Buckland ST, Anderson DR, Burnham KP, Laake JL, Borchers DL, Thomas L. 2004. Advanced distance sampling: Estimating abundance of biological populations. Oxford (UK): Oxford University Press.

Burnham KP, Anderson DR. 2002. Model selection and multimodel inference: A practical information-theoretic approach. $2^{\text {nd }}$ ed. New York: Springer.

Elliott PF. 1988. Foraging behavior of a central-place forager: field tests of theoretical predictions. Am Nat 131:159-174.

Enright NJ, Marsula R, Lamont BB, et al. 1998. The ecological significance of canopy seed storage in fire-prone environments: a model for non-sprouting shrubs. J Ecol 86:946959.

Fortin MJ, Dale MRT. 2005. Spatial Analysis: A Guide for Ecologists. Cambridge University Press, Cambridge, UK.

Gauthier S, Bergeron Y, Simon JP. 1996. Effects of fire regime on the serotiny level of jack pine. J Ecol 84:539-548.
Keeley JE, Zedler PH. 1998. Evolution of life histories in Pinus. pp 219-249 in Ecology and biogeography of Pinus. Cambridge University Press, Cambridge, UK .

Perry DA, Lotan JE. 1979. A model of fire selection for serotiny in lodgepole pine. Evolution 33:958-968.

Schoennagel T, Turner MG, Romme WH. 2003. The influence of fire interval and serotiny on postfire lodgepole pine density in Yellowstone National Park. Ecology 84:2967-2978.

Smith CC. 1968. The adaptive nature of social organization in the genus of three squirrels Tamiasciurus. Ecol Monogr 38:31-63.

Smith CC. 1970. The coevolution of pine squirrels (Tamiasciurus) and conifers. Ecol Monogr 40:349-371.

Thomas L, Buckland ST, Rexstad EA, Laake JL, Strindberg S, Hedley SL, Bishop JRB, Marques TA, Burnham KP. 2010. Distance software: design and analysis of distance sampling surveys for estimating population size. Journal of Applied Ecology 47: 5-14.

Tinker DB, Romme WH, Hargrove WW, et al. 1994. Landscape-scale heterogeneity in lodgepole pine serotiny. Canadian J For Res 24:897903.

Turner MG, Romme WH, Tinker DB. 2003. Surprises and lessons from the 1988 Yellowstone fires. Front Ecol Environ 1:351-358.

Turner MG, Tinker DB, Romme WH, et al. 2004. Landscape patterns of sapling density, leaf area, and aboveground net primary production in postfire lodgepole pine forests, Yellowstone National Park (USA). Ecosystems 7:751-775. 